\title{
Knowledge Management in Vietnameses Mall and Medium Enterprises :
}

\section{Review of Literature}

\author{
Hanh-Thao Le ${ }^{1, *}$ \\ ${ }^{1}$ Ph.D Student in Business Management, College of Business, Southern Taiwan University of Science and Technology Tainan, Taiwan \\ 1da51g209@stust.edu.tw* \\ * corresponding author
}

(Received June 1, 2021 Revised June 10, 2021 Accepted June 28, 2021, Available online July 1, 2021)

\begin{abstract}
This paper aims to review and analyze Knowledge Management (KM) in small and medium enterprises (SMEs) in the specific context of the Vietnamese economy using a literature review methodology. The important role of KM has been greatly emphasized in terms of achieving and maintaining a company's competitive advantage. However, most of the previous studies were conceptually based and examined empirically in developed, developed and industrialized countries and from a broad perspective. Meanwhile, little effort has been made to address the relative importance of KM in organizational infrastructure capabilities in the context of developing and less developed Asian countries such as Vietnam. The results show some of the current situation in Vietnam and related recommendations.
\end{abstract}

Keywords: Knowledge Management; Small and medium enterprises; Vietnamese context; Literature review methodology;

\section{Introduction}

Knowledge has become a key strategic asset for the 21 st century. Today, natural resources, capital and labor are now being replaced by knowledge as one of the most promising and advanced resources from which socioeconomic wealth can be generated. Almost every organization recognizes the importance of assessing knowledge and investing in developing the best strategies for identifying, developing and implementing knowledge assets as a way to succeed.

There is a saying: "knowledge will radically and fundamentally change the economy". One thing is absolutely certain in this rapidly changing world: The best knowledge will always be needed.

Today, knowledge management (KM) is applied worldwide, across all industrial sectors, public and private organizations, international institutions and charities (Durst \& Edvardsson, 2013). More importantly, effective KM is now considered to be "the 'key driver of new knowledge and new ideas' for the innovation process (Young, From Knowledge to Innovation, 2010). In business, the main function of KM is to facilitate the creation of new knowledge which then becomes the company's competitive advantage (Young, From Knowledge to Innovation, 2010). Thus, KM is getting increasing attention by academics and practitioners with the aim of optimally developing sustainable companies.

There is a considerable amount of existing research with a very strong theoretical foundation on the topic of KM, with a major focus on processes and structures in large organizations, with more advanced market case studies, to improve performance and competitive advantage, assuming that the organization already has the resources necessary power in their hands. However, in the context of small and medium enterprises (SMEs), it was found that the topic of knowledge utilization research still seems rather limited (Durst \& Edvardsson, 2012). This is unsatisfactory given the role and number of SMEs in most of the world's economies, as SMEs play an important role in both developing and developed economies (Vasudevan \& Chawan, 2014). As stated by several studies: SMEs are the engine of economic growth in the industrial world (Massaro, Karen Handley, \& Dumay, 2016). 
Based on the regional aspect, the focus of research in the context of the Asia Pacific region is still in the development stage, especially for KM issues and their implementation in SMEs in certain countries such as Vietnam (Nguyen H. T., 2011). Vietnam is a developing country, a developing Asian country, where a socialist market economy, Confucian culture and majority of SMEs exist (Nguyen, Neck, \& Nguyen, 2008). The country is late in the development of a knowledge-based economy, where KM is still considered a rather expensive management tool.

This paper builds on a review of KM in SMEs in general, and in more detail, the application of KM in SMEs in Vietnam under a knowledge-based approach to KM. The main implication is about putting this new management tool into practice for SMEs in such an economy with its own specific features, characteristics and conditions. Findings reveal promising areas for development, comparative studies such as those focusing on developing and under-investigated areas are encouraged especially for other Asian developing countries with a similar Confucian economic and cultural environment. The method used in this paper is a literature review approach. Following this approach, it was argued that such studies could "contribute to developing new research pathways and questions by providing a foundation" for future research (Massaro, Karen Handley, \& Dumay, 2016).

\section{Literature Review}

\subsection{A resource-based view of Knowledge Management}

The resource-based view of the firm is based on the relationship of the firm's internal strengths and specific resources to maintain competitive advantage and counter threats in the market (Riahi-Belkaoui, 2003). Adopted as an extension of the resource-based view, the knowledge-based approach defines the firm as an entity that generates, integrates and distributes knowledge (Lopez, 2005). Therefore, KM capabilities are at the center of this perspective to keep companies competitive in today's dynamic market (Nguyen, Neck, \& Nguyen, 2008).

From a resource-based and knowledge-based perspective, previous literature identified that while technology, culture, and structure are rare, firm-specific resources are more likely to serve as sources of organizational capability (Nguyen, Neck, \& Nguyen, 2008). Meanwhile, KM enablers on company performance include structure, culture, people, and technology (Lee \& Choi, 2003); with structure, culture, and people as a social perspective, and specific information technology as a technical perspective (Chuang, 2004). In addition, most of these studies are based and examined in developed, developed and emerging industries, and focus heavily on large companies.

For aspects of technical KM capabilities, information technology (IT) is often described as the main business resource and the main source for achieving long-term competitive advantage (Chuang, 2004). However, some negative correlation results of studies indicate that IT can indeed worsen a company's competitive position due to the possibility of imitation of IT by competitors, therefore companies should not use IT alone to take advantage of other company-specific intangible resources (Clemons \& Row, 1991). In the context of KM, IT should be combined with other dimensions of KM capabilities to demonstrate and significantly enhance its impact on the firm's competitive advantage (Nguyen, Neck, \& Nguyen, 2008).

With the contribution component of social KM capabilities, it is the amount of actual and potential available resources that come from the network of relationships held within the social unit. There are important dimensions of organizational structure, culture and people that have been found to be key to driving various activities related to successful implementation of the differentiating factors of successful companies (Lee \& Choi, 2003). These valuable resources typically develop over a long period of time through the accumulation of operating experience, and thus, when combined effectively with the technical KM dimensions, they will become an organization's unique KM infrastructure capability that provides a sustainable competitive advantage (Chuang, 2004). 


\subsection{Knowledge Management within SMEs}

\subsubsection{Overview of management and structures in SMEs}

Businesses can be classified by size. SMEs tend to differ from large ones in many ways, such as in company structure, processes, procedures and behavior (Nguyen H. T., 2011). SMEs do not manage knowledge in the same way that large SMEs do, therefore it is wrong to assume that all companies are the same. The problems that will be faced by SME businesses will not just be a scaled down replica of the experience of large companies (Durst \& Edvardsson, 2012).

In the situation of small-scale companies that have a flat structure and free-floating management style, they tend to be informal, non-bureaucratic and there are few rules among organizations (Durst \& Edvardsson, 2013). Control tends to be based on the owner-manager's personal vision and policies are largely absent (Daft, 2007). In such an environment, generally business planning and decision-making processes are taken around the central position of a single individual (Culkin \& Smith, 2000). These same people are specifically responsible for recognizing the benefits associated with knowledge management in company operations. It should be noted that the attitude of top managers to risk or employee resistance to innovation is the main obstacle in any organizational change (Vasudevan \& Chawan, 2014).

A large number of small companies suffer from insufficient time for strategic issues, as well as a lack of financial resources and technological expertise, which often results in in many cases that knowledge ends up being stored in the minds of owners and a few key employees, rather than being recorded and shared through an organization. (Wong \& Aspinwall, 2004).

Most SMEs do not have explicit policies targeted at strategic knowledge management, and they tend to treat knowledge management at the system and instrument level (Hutchinson \& Quintas, 2008). SMEs are also more likely to emphasize tacit knowledge management, and their communication channels are more external (between companies) than internal (between the organizations themselves), and often consider knowledge management activities - such as knowledge sharing - to be time consuming. consuming and expensive (Durst \& Edvardsson, 2013).

SMEs appear to be less advanced in terms of knowledge construction, weaker in systematic discussion of tacit knowledge sharing, and prefer a short-term, unstructured approach to organizational learning (McAdam \& Reid, 2001). In many cases, SME managers even try to prevent the outflow of knowledge from their companies; thus they block knowledge sharing channels (Bozbura, 2007). This can undermine the potential benefits of knowledge management.

\subsubsection{Knowledge sharing issues in SMEs}

Among KM processes, knowledge sharing (or knowledge transfer) is considered the most critical KM process. Among the many KM studies, only a few specifically target knowledge sharing. This is discussed because most knowledge in SMEs is tacit, so informal face-to-face social interaction is the most effective technique, where usually the sharing climate appears to be informal (McAdam \& Reid, 2001). However, the number of SMEs that explicitly exploit knowledge sharing is still limited.

The solution for knowledge sharing in SMEs is to create a suitable working environment for employees to organize social activities for sharing purposes. Since the size of the SME is assumed to be small, this will be an opportunity for easier control and direction. If the business owner has a strong commitment to implementing KM, then there will be no significant obstacles for the company.

\subsubsection{The relationship between Knowledge Management and Organizational performance}

There are a number of observations that show a positive relationship between knowledge management and organizational performance (Durst \& Edvardsson, 2013). 
KM must result in the achievement of better, and even exceeding, individual and organizational goals. The goal of KM should not only be to become more knowledgeable, but to be able to create, transfer and apply knowledge with the aim of achieving better goals.

Recent studies highlight that SMEs can benefit from KM activities with regard to employee development, innovation, customer satisfaction and organizational success (Durst \& Edvardsson, 2013). Small businesses can benefit from implementing knowledge management activities, resulting in organizational success, such as sales growth, fewer losses, increased productivity and process improvements, employee development, increased customer satisfaction, innovation, creativity and knowledge creation, and improved external relations with stakeholders. other. company.

$\mathrm{KM}$, as it may provide managers and business owners with an effective tool to address their most challenging problem - the shortage of competent employees to (1) stabilize their existing business, and then (2) expand it. This is evidenced by some SMEs where CEOs struggle to apply KM unconsciously to solve the problems of "loss of knowledge" and "lack of competent employees" (Nguyen \& Alam, 2007).

\subsubsection{To enable effective Knowledge Management in SMEs}

We should bear in mind, effective Knowledge Management is a timeless and changeless principle. Every organization needs to invest in creating and implementing the best knowledge networks, processes, methods, tools and technologies. This will enable them to learn, create new knowledge, and apply the best knowledge much faster. Every individual who wants to successfully participate in the rapidly growing global knowledge economy should as well consider the development of their personal knowledge management competencies as an "essential life skill" in this era.

\subsection{Knowledge Management in Vietnamese SMEs}

\subsubsection{Overview of management and structures in SMEs}

It is stated that the cultural, economic, and political context of Vietnam shapes entrepreneurial business activities and greatly influences the ability of companies to achieve competitive advantage and business success (Nguyen \& Alam, 2007).

Historically, Vietnam has been heavily influenced by Confucian Chinese culture. Although there is much debate on this topic, the interrelationship between Neo Confucianism and Communism is recognized as a major distinct feature of the business environment in Vietnam. It has also shaped organizational culture and has been considered a reference system that governs ethical ways of doing business in the country (Baughn, Cao, Le, Lim, \& Neupert, 2006). In addition, the role of culture in shaping organizational norms and practices strongly emphasizes collectivism and commitment among an organization (King-Kauanui, Su, \& Ashley-Cotleur, 2006).

During the developing stage, Vietnam had long been exposed to Western values from the French colonialism in the 1880s to the 1950s and the US intervention until 1975 (Dieu, 2003), and more than half of the Vietnamese population was born. post-Vietnam War tend to be influenced by Western values and lifestyle (Nguyen, Neck, \& Nguyen, 2008). It can maintain the promising potential implications of western-based managerial practice with a selective approach that carefully incorporates Confucian philosophy, socialist market philosophy, and adaptation of new managerial techniques.

For many young Vietnamese, Confucian culture is traditional values and beliefs, while the Western lifestyle and management approach is considered ideal. Vietnamese entrepreneurs are also getting younger and better educated: $49.7 \%$ of business owners in Vietnam are under the age of 39 (Tran, 2015), 72\% with a bachelor's degree and beyond (Nguyen, Neck, \& Nguyen, 2008). Therefore, it is believed that they are more flexible and willing to change to enhance and enhance innovation and competitiveness. It was also emphasized that the existence of a risk aversion attitude is still prominent. 
It has also been noted by many scholars that the adopted Western-based managerial practice must differ from the original model due to the different business conditions and cultures of the country. Moreover, they have to be implemented in stages and can therefore limit the flexibility of an organization.

Vietnam's economic development model is mainly based on low labor costs and intensive capital investment (Nguyen H. T., 2011). To achieve the strategic goal of becoming a middle-income country, Vietnam's economy needs to increase productivity and competitiveness as the core of growth. To achieve that, Vietnam's economic structure should not become more productive by relying solely on low labor costs and capital investment as it is still lagging behind in development towards a knowledge-based economy, according to a World Bank survey. To improve the ranking of a country, Vietnam should focus on the basic index KEI (Knowledge Economy Index), which is about the country's environment to show the level of facilitating the effective use of knowledge for economic development.

In the "Knowledge Management in Asia: Experiences and Lesson" report of the APO survey on the status of KM, it is revealed that $\mathrm{KM}$, as well as other advanced management tools, is "a very new concept in Vietnam in general and in companies and state organizations in particular" ( $\mathrm{Vu}, 2008)$. It also stated that, however, there was already a "good basis/promotion for future KM applications, including KM implementation in the SME sector" (Vu, 2008). It helps raise good awareness about the knowledge-based economy, government efforts to develop information and communication technology, high priority of science and technology in official policy documents, government programs to support the development of knowledge assets in enterprises, awareness of intellectual property rights protection, and increasing the number of companies that have implemented international standard management tools, and government programs to promote SMEs (Nguyen HT, 2011).

\subsubsection{SMEs in Vietnam}

According to Government Decree 90/2001/ND-CP of 23 November 2001, SMEs in Vietnam are defined as 'independent production and business enterprises, which make business registrations in accordance with current legal provisions, each with registered capital not exceeding VND 10 billion or annual workforce does not exceed 300 people ( 10 billion VND $\sim 600,000$ USD -at exchange rate in 2001).

This means that in practice SMEs include all companies established and operating under the Company Law, BUMN Law, Cooperative Law, and business households that are registered under Government Decree no. 02/2000/ND-CP from the Government February 3, 2000 regarding business registration. In other words, SMEs include many forms of business organization such as state-owned companies, private companies, limited companies, joint stock companies, cooperatives and home or family businesses.

After that, Decree 56/2009/ND-CP came into force on August 20, 2009, replacing Government Decree 90/2001/ND-CP dated November 23, 2001 on supporting the development of SMEs. This decree defines SMEs as follows: Small and Medium Enterprises are business entities that have registered their businesses according to law and are divided into three levels: very small, small and medium according to the size of their total capital (equivalent to total capital). assets identified on the company's accounting balance) or the average annual number of employees (total capital is the priority criterion).

The current definition has been updated to reflect the changing practice of business in Vietnam. While manufacturing companies are considered small with 100 employees (most of them are workers - The number of workers is large because our current business model is still labour-intensive), trading or service companies with more than 50 employees are considered medium-sized companies. The contribution of SMEs to the socio-economic development of the country is recognized, especially in job creation and income generation as indicators of poverty alleviation "The private sector is responsible for almost all new jobs created in Vietnam between 2000 and 2008" (Tran, 2015). The number of SMEs is increasing and becoming the most dynamic driver of the national economy.

In a 2011 paper, it was mentioned that strategic plans are not common among SMEs in Vietnam, with CEOs usually confused between business plans, strategic plans, and even between dreams about what they want to lead the 
organization (Nguyen HT, 2011). Almost SME CEOs manage companies solely on the basis of their practical experience, and in some cases they lack consistency in management. Conflict occurs when the responsibilities of the CEO and other members of top management are unclear. Another difficulty with KM is about human resources; with the main problem is "loss of knowledge" because key people are "stolen" by competitors. Also, companies in Vietnam do not invest much in training their employees due to lack of long-term commitment from workers.

Another aspect is that most companies don't really care about management support software unless it's really useful for day-to-day business. Some of them even have poor computer skills and rarely work at the computer.

We should mention about the role of state-owned enterprises (BUMN) as well. Most industries Most industries come from BUMN (41\% as joint stock, joint venture, or wholly owned by foreigners, $22 \%$ BUMN, and only $37 \%$ private companies) which are entitled to State policies such as special credit loans, tax incentives, assistance training, support in importing equipment and transferring technology (Nguyen, Neck, \& Nguyen, 2008). They also receive more preferential support from their own governing bodies and have easier access to resources than private SMEs (Nguyen \& Alam, 2007). These special characteristics, coupled with the emerging private business sector and booming booming economy, have created a more intensive and dynamic competitive landscape for the SME sector in Vietnam.

\subsubsection{Knowledge Management in Vietnamese SMEs}

\subsubsection{Findings of Knowledge Management in Vietnamese SMEs}

For organizational culture, it is consistent with previous studies that cultural elements have a strong impact on Vietnamese business activities and business success (Baughn, Cao, Le, Lim, \& Neupert, 2006). Cultural factors can influence, both positively and negatively, an entrepreneur's willingness to take risks and make business decisions. Vietnam's specific cultural attributes are critical to its entrepreneurial culture which, in turn, positively affects an organization's KM capabilities and competitiveness (Nguyen, Neck, \& Nguyen, 2008).

For information technology, technical KM capability was found to positively and significantly affect the company's competitive advantage. The demands of Vietnamese entrepreneurs for technological innovation are relatively low (Le, 2006) The average expenditure of Vietnamese SMEs for this purpose accounts for only $0.2-0.3 \%$ of total revenue, compared to 5\% for Indian SMEs or 10\% for Korean SMEs ( Le , 2006), which points out that SMEs do not provide to be able to upgrade their technology and equipment to a high level of technological development. This may be due to inadequate manpower, inadequate capital and managerial skills, when most of their equipment is based on traditional technology operated under manual or semi-automatic control, which is outdated even by several generations of technology (Nguyen \& Alam). ). , 2007). Given the intensive, dynamic, competitive and rapidly growing business trend in Vietnam, this requires companies to upgrade their technology equipment and information systems in order to gain and maintain a competitive advantage.

The other two components, namely organizational structure and human factors, although proved to be positively and significantly correlated with other organizational factors in many previous literatures. However, in the context of Vietnamese SMEs, they do not uniquely and significantly contribute to the company's competitive advantage.

For organizational structure, the reason may be "Vietnamese companies that have emerged from central planning to some form of market socialism tend to be bureaucratic" (Nguyen, Neck, \& Nguyen, 2008). It is understood that they are more likely to rely on loyalty, commitment, regulations and formal organizational structures rather than future orientation. This is also explained by the strong influence of Confucian culture, Vietnamese managers tend to accept hierarchical and formal management structures, place less emphasis on individual actions and achievements, and are less willing to accept change (Berrell, Wright, \& Hoa, 1999). With the selective adoption and modification of Western-based managerial practices as previously mentioned, this explains why organizational structure relies heavily on other dimensions of social KM and does not make a unique and significant contribution to corporate CA.

For human KM resource factors, it was shown that Vietnam's human resource management practices rely more heavily on human labor factors than those found elsewhere (King-Kauanui, Su, \& Ashley-Cotleur, 2006). However, 
despite the tendency to emphasize collectivism, Vietnamese may not always work as an effective team as is generally expected due to the lack of well-defined common goals in group work while encouraging increased popularity in pursuit of their personal goals (VVTuan \& Napier, 2000). That is why human KM resources are considered not to have a significant contribution to the organization.

Moreover, despite the long-term benefits that KM can bring to companies, it is difficult to attract business in the context of SME resources which are so scarce in Vietnam unless it is considered a tool for them to solve day-to-day operational problems first.

\subsubsection{SMEs managers' willingness to adapt Knowledge Management as a management tool}

In a paper by Nguyen H. T. in 2011, he interviewed 20 SMEs. Generally, business people do not know or know little about KM, the situation is the same even for policy makers or government authorities who are officially in charge of supporting SMEs in the country.

The result is that $13 / 20$ of them want to apply KM to their business, after discussing KM and its benefits, hope that KM can help solve their current problems and become more sustainable. Another 5 companies showed interest, but they doubted whether KM could work in their company. The remaining 2 said that KM seemed too theoretical, difficult to implement, and not very necessary for their business. 
The seven main (potential) KM problems for Vietnamese SMEs were defined as:

- IT usage

- Advanced management tools usage

- Knowledge sharing

- Training effectiveness

- Report system

- Harmfulness caused by high staff turnover

- Innovation

\subsubsection{To apply Knowledge Management in Vietnamese SMEs}

Because KM is rooted in large, resource-rich companies, it is considered an "expensive" management tool. However, there are several ways to implement it depending on the available resources and company goals.

KM can help companies identify, capture, and store the most valuable knowledge available, then facilitate employees to apply it in daily business activities. At higher levels of $\mathrm{KM}$, based on this solid foundation, companies will be able to quickly learn new knowledge from other sources and adapt to changing business environments. In this way, KM will bring solutions to SMEs in both the short and long term.

One thing to do to start KM in a small business, IT system requirements or other technical systems are required; however it is not a priority because the ability to use IT employees is limited. Minimum IT investment is sufficient to facilitate communication and knowledge exchange. Instead, SMEs should start with a personalization strategy for an effective mechanism. A clear strategy is always necessary for the success of any plan.

To ensure the success of KM programs in SMEs, direct involvement of managers or company owners with absolute commitment to change is essential. While KM aims to consolidate organizational knowledge as a company's core value, it still appears to be risky for employees to "lose their bargaining power". Thus, supportive policies to demonstrate the company's long-term commitment to employees as well as to demonstrate adequate recognition to contributors are required.

KM in SMEs is about changing organizational work and sharing attitudes and behaviors. Managers and owners of SMEs need to clearly understand the benefits and be prepared to accept short-term trade-offs. Attitude and job skills training for employees is mandatory to ensure that the benefits of KM can be utilized effectively. Employees must play a subject role in the KM process through daily activities.

\section{Conclusion}

\subsection{Values of the paper}

This paper attempts to systematically and empirically review the utility of KM among SMEs in general, and then investigates the current picture of KM perceptions, practices, and status in Vietnam.

Consistent with general agreement in the literature, it is argued that there is a significant positive correlation between the components of $\mathrm{KM}$ infrastructure capabilities as well as between them and the competitive advantage of organizations. However, in today's Vietnam-specific environment, only two important factors of the KM dimensions of culture and technology make a uniquely significant contribution to the company's competitive advantage, with culture having a great influence. These results highlight the need to consider culture as a dominant issue in KM to improve organizational outcomes.

\subsection{Implications for Vietnamese SMEs}

From the literature, it is evident that KM is a must for good management. It can even be said that KM plays a very important role for the stable development of SMEs as a viable solution for day-to-day business. 
In terms of practical implications, this paper attempts to provide Vietnamese business executives with a better understanding, especially from SMEs in the construction industry on how companies need to be managed effectively to enhance their overall KM infrastructure capabilities to leverage, exploit and maintain. a competitive advantage. In addition to considering the combination of technical and social KM resources, practicing managers should investigate and take full advantage of IT in relation to other key organizational factors to overcome cultural barriers and strengthen their contribution to long-term performance.

The role of authority is also very important. Vietnamese businesses have shown a real need to adopt KM for their sustainable development. Therefore, the government should pay more attention to this issue. A national practical KM program should be designed and launched immediately to meet the requirements of reality in the short term and for the competitive advantage of the country's economy in the long term.

\subsection{Future recommendations}

Furthermore, more systematic and larger research can be carried out in other sectors to provide a more comprehensive picture of KM in Vietnam, as well as directly to business people in implementing KM into their business.

Another direction for the study is to identify whether a relationship between firm characteristics and KM related issues exists or not, and to explain the nature of how these factors will affect firm practices in a given context.

Similar application can be made with improvements in measurement and different aspects in other developing countries, where KM is still under-appreciated. Must be in strong belief in the great benefits KM can bring to companies and the national economy.

\section{References}

[1] Baughn, C., Cao, J., Le, L., Lim, V., \& Neupert, K. (2006). Normative, social and cognitive predictors of entrepreneurial interest in China, Vietnam, and the Philippines. Journal of developmental entrepreneurship, 11 (1), 55-77.

[2] Berrell, M., Wright, P., \& Hoa, T. (1999). The influence of culture on managerial behavior. The Journal of Management, 18 (7), 578.

[3] Chuang, S. (2004). A resource-based perspective on knowledge management capability and competitive advantage: an empirical investigation. Expert Systems with Applications, 459-465.

[4] Culkin, N., \& Smith, D. (2000). An emotional business: a guide to understanding the motivations of small business decision takers. Qualitative Market Research: An International Journal, 3 (3), 145-157.

[5] Dieu, M. M. (2003). Culture and customs of Vietnam. Westport: Greenwood Press.

[6] Durst, S., \& Edvardsson, I. R. (2012). Knowledge Management in SMEs: A Literature Review. Journal of Knowledge Management, 16(6), 879-903.

[7] Durst, S., \& Edvardsson, I. R. (2013). The Benefits of Knowledge Management in Small And Medium-Sized Enterprises. Procedia -Social and Behavioral Sciences, 251-354.

[8] Hutchinson, V., \& Quintas, P. (2008). Do SMEs do Knowledge Management? Or simply manage what they know? International Small Business Journal , 26 (2), 131-154.

[9] King-Kauanui, S., Su, D., \& Ashley-Cotleur, C. (2006). Impact of Human resource Management: SMEs performance in Vietnam. Journal of developmental entrepreneurship, 11 (1), 79-95.

[10] Le, D. (2006). Businessmen, business entrepreneurs and economic reform. Ho Chi Minh City: The Youth Publishing House. Saigon Economic Times.

[11] Lee, H., \& Choi, B. (2003). Knowledge management enablers, processes, and organizational performance: an integrative view and empirical examination. Journal of Management Information Systems, 20 (1), 179-228.

[12] Lopez, S.V. (2005). Competitive advantage and strategy formulation: The key role of dynamic capabilities. Management Decision , 43 (5), 661-669. 
[13] Massaro, M., Karen Handley, C. B., \& Dumay, J. (2016). Knowledge management in small and medium enterprises: A structured literature review. Journal of Knowledge Management, 20(2), 258-291.

[14] McAdam, M., \& Reid, R. (2001). SME and large organization perceptions of knowledge management: comparisons and contrasts. Journal of Knowledge Management, 5(3), 231-241.

[15] Nguyen, H. T. (2011). Knowledge Management in Small and Medium Sized Enterprises in Developing Countries(Case study: Vietnam).(Doctoral Dissertation), Tomas Bata University in Zlin.

[16] Nguyen, Q. T., Neck, P. A., \& Nguyen, T. H. (2008). The impact of knowledge management infrastructure on organizational competitiveness in a Confucian-socialist market economy. The 5th International Conference on Service Systems and Service Management, (pp. 1-6). Melbourne, Australia.

[17]Nguyen, T., \& Alam, Q. (2007). State and Market relationships: Public financial policy support for SMEs growth in Vietnam. Proceedings of the Seventh International Business IBR conference. Sydney, Australia.

[18] Thi Thanh Hai, T. (2015). Challenges of Small and Medium-Sized Enterprises (SMEs) In Vietnam during the Process of Integration into the ASEAN Economic Community (AEC). International Journal of Accounting and Financial Reporting, 5 (2), 133-143.

[19] V.V. Tuan, \& Napier, N. (2000). Paradoxes in Vietnam and America: Lessons earned. Human resource planning , 23 (3), 8-10.

[20] Vu, H. D. (2008). Knowledge management in Vietnam. Tokyo: The Asian Productivity Organization.

[21] Wong, K., \& Aspinwall, E. (2004). Characterizing knowledge management in the small business environment. Journal of Knowledge Management, 8(3), 44-61. 